\title{
Performance Analysis of a Biodiesel-Fired Engine for Cogeneration
}

\author{
Luigi Falbo ${ }^{1}$, Ernesto Ramundo
}

${ }^{1}$ DIMEG, Department of Mechanical, Energy and Management Engineering, Università della Calabria, Via P. Bucci, Cubo 44C, 87036 Rende, Italy

\begin{abstract}
The continuous demand to reduce both the pollutant emissions and the greenhouse gas (GHG) is increasing the use of alternative fuels as biodiesel in direct-injection compression ignition engines under combined heat and power (CHP) configuration. Although the biodiesel has different thermophysical properties compared to the standard diesel, it can be used in compression ignition engines without significant modifications. However, the pure biodiesel and biodiesel/diesel blends provide different performance and combustion characteristics with respect to the standard diesel engine. In order to estimate the behaviour of a micro-CHP system fuelled with biodiesel, a zero dimensional (0D) numerical model was development. This model is based on a single zone model and predicts the behaviour of a biodiesel/diesel blend-fired engine at full and partial load in terms of electrical efficiency, thermal efficiency and specific fuel consumption. Notwithstanding the biodiesel/diesel blend reveals lower performance in terms of electric and thermal efficiencies, can be used in CHP systems preserving the environmental sustainability avoiding significant modifications in the engine architecture.
\end{abstract}

\section{Introduction}

It is well known that Diesel engines are widely used for applications in the power generation, cogeneration and automotive sector. Owing to the rapid depletion and rising prices of petroleum, as well as to the strict emission regulations [1], there is a bunch of scientific literature on alternative fuels in diesel engines. The biodiesel is an attractive, renewable and environment friendly alternative fuel for diesel engines [2]. Furthermore, the use of low amount of biodiesel in blend with conventional diesel fuel in compression ignition engines leads to irrelevant modifications in the engine architecture [3]. Numerous studies on mathematical models of internal combustion engine were widely investigated. These models can be divided in thermodynamic models, which includes zero-dimensional (0D)/one-dimensional (1D) models and fluid dynamics models (Computational Fluid Dynamics, CFD) often called multidimensional models [4]. These works investigate the heat release calculation, the heat transfer modelling, the knock phenomenon in spark ignition engine [59] and the engine behaviour in multi-source energy systems [10]. Other researcher focused on turbulence modeling during the intake process [11-15], as well as the modeling of the emission control during the exhaust process [16-17].

The zero-dimensional models, based on the first law of thermodynamic, use semi-empirical relationships to describe each thermodynamic process occurring in the engine operating cycle. The relative simplicity of implementation, the low computational cost, the ability to perform parametric analysis, as well as the good accuracy of these type of models make them very attractive.

Several studies on mathematical models of compression ignition engine fuelled with diesel were widely investigated with different methods and complexity [18-22]. However, few works related to 0D models of compression ignition fuelled with diesel/biodiesel blends are present in the literature. Abbe et al. [23] developed a 0D model on biodiesel combustion in compression ignition engine in order to predict the combustion parameters and the NOx emissions. The effect of engine speed and compression ratio on the performance of a diesel engine fuelled with diesel, karanja methyl ester biodiesel and their blends are analysed by Gogoi et al [24] by means of a 0D model. The model predicted an increase of the brake thermal efficiency for blends with various biodiesel concentrations, from 20 to $60 \%$, and a higher cylinder pressure rate for the blends with respect to diesel fuel. Ramdhas et al. [25] developed a 0D model for the prediction of the performance 
of a compression ignition engine fuelled with any type of hydrocarbon-fuel, diesel, biodiesel and their blends. The model results showed that both the cylinder pressure peak and the brake thermal efficiency increase when the compression ratio increases and air fuel ratio decreases. Furthermore, the model results are in accordance with experimental data.

In the current work, a preliminary mathematical model of compression ignition engine fuelled with pure diesel fuel (B0) and a diesel/biodiesel blend (B30) is developed in Matlab. The mathematical model is based on a 0D-thermodynamic code, which predicts the performance of the internal combustion engine fuelled with biodiesel fuel in terms of, electric efficiency, thermal efficiency and specific fuel consumption (SFC) at different loads and at a given engine speed.

\section{Materials and Method}

\subsection{Engine and Fuel Description}

The engine of the current study, which develops a mechanical power output of $11 \mathrm{~kW}$ at $2200 \mathrm{rpm}$, is a compression ignition engine, four stroke and water cooled. The engine specifications and fuel properties are used as input in the model and are reported in Table 1 and Table 2, respectively. Data refer to the engine investigated by Qi et al [26], who carried out only experimental tests on the current engine at $1500 \mathrm{rpm}$ engine speed fuelled with diesel and diesel/biodiesel blends.

Table 1. Diesel engine specifications

\begin{tabular}{|l|l|}
\hline Engine design & Single Cylinder, DI, 4-stroke, compression ignition \\
\hline Bore & $105 \mathrm{~mm}$ \\
\hline Stroke & $115 \mathrm{~mm}$ \\
\hline Connecting rod & $185 \mathrm{~mm}$ \\
\hline Compression ratio & $16.5: 1$ \\
\hline Displacement & $996 \mathrm{cc}$ \\
\hline Rated Power & $11 \mathrm{~kW}$ \\
\hline Rated Speed & $2200 \mathrm{rpm}$ \\
\hline Fuel Injection Timing (FIT) & $22^{\circ} \mathrm{BTSC}$ (static) \\
\hline Injector Holes & $4 \times 0.32$ mm diameter \\
\hline Injector opening Pressure & $180 \mathrm{bar}$ \\
\hline
\end{tabular}

Table 2. Fuel Properties

\begin{tabular}{|l|c|c|}
\hline Properties & B0 & B30 \\
\hline Density $[\mathrm{kg} / \mathrm{m} 3]$ & 820 & 830 \\
\hline Kinematic viscosity at $20^{\circ} \mathrm{C}\left[\mathrm{mm}^{2} / \mathrm{s}\right]$ & 4.8 & 5.1 \\
\hline Lower heating value $[\mathrm{MJ} / \mathrm{kg}]$ & 42.50 & 41.34 \\
\hline Flash point $\left[{ }^{\circ} \mathrm{C}\right]$ & 67 & 81 \\
\hline Cold filter clogging temperature $\left[{ }^{\circ} \mathrm{C}\right]$ & 3 & 3 \\
\hline Solidifying point $\left[{ }^{\circ} \mathrm{C}\right]$ & -6 & -6 \\
\hline Acid value $[\mathrm{mg} \mathrm{KOH} / \mathrm{g}]$ & 0.03 & 0.3 \\
\hline
\end{tabular}

The biodiesel fuel is derived from the transesterification of soybean crude oil with methanol $(\mathrm{CH} 3 \mathrm{OH})$ catalysed by potassium hydroxide $(\mathrm{KOH})$. A detailed description of the engine, experimental apparatus, test procedure, operating conditions as well as production procedure and properties of biodiesel can be found in [26]. In order to analyse a microCHP system with the current engine as prime mover a schematic layout of the micro-CHP system is proposed in Figure 1. The system recovers thermal power both from the heat transfer rate to the cooling fluid and from the exhaust gas heat by means of two different heat exchangers. The heat exchanger (A) recovers the thermal power from the cooling circuit while the heat exchanger (B) recovers the exhaust gas heat. Furthermore, a water circuit to recovery the thermal power is adopted. 


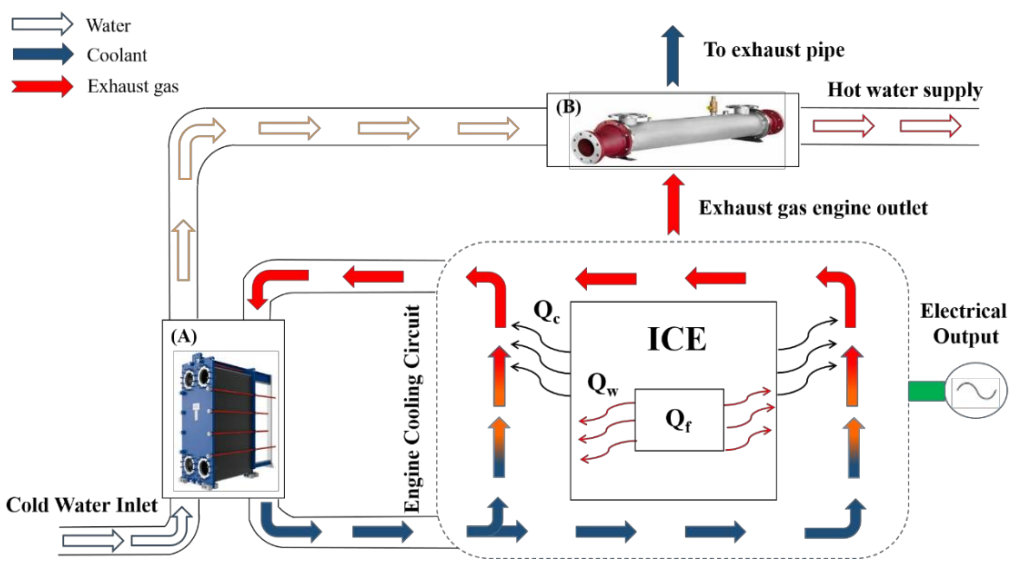

Figure 1. Micro-CHP system layout.

\subsection{Engine Mathematical Model}

The proposed thermodynamic model has been developed to evaluate the performance of the ICE fuelled with biodiesel, diesel and biodiesel/diesel blends. Specifically, a single-zone approach [27] has been used to evaluate the performance of the biodiesel-fired ICE unit in terms of electric efficiency, cooling thermal efficiency and exhaust thermal efficiency. In the single zone model, the cylinder charge is assumed uniform in both composition and temperature, the fuel injected in the cylinder is assumed to be mixing instantaneously with the cylinder charge, therefore the gas mixture is considered as an ideal gas. The first law of thermodynamic for a closed system can be expressed in term of the cylinder pressure as a function of the crank angle $\theta$ :

$$
\frac{d P}{d \theta}=\frac{\gamma-1}{V}\left(\frac{d Q_{f}}{d \theta}-\frac{d Q_{w}}{d \theta}\right)-\gamma \frac{P}{V} \frac{d V}{d \theta}
$$

where $P$ is the cylinder pressure, $V$ is the instantaneous cylinder volume and $\gamma$ is the specific heat ratio. Modeling the gross-heat release $d Q_{f} / d \theta$, the heat-transfer rate to the walls $d Q_{w} / d \theta$ and the instantaneous cylinder volume $d V / d \theta$, the equation (2) predicts the pressure in the combustion chamber.

The ignition delay (ID) is an important parameter for the combustion process in diesel engine because determines the ignition point and therefore the start of combustion (SOC).

The ID is defined as the difference between the SOC and the start of the dynamic injection timing (DIT). In this work, an empirical formula for the ID determination developed by Hardenberg and Hase [28] is used.

The heat release rate by combustion can be modelled as a function of mass fraction burned at any crank angle.

$$
\frac{d Q_{f}}{d \theta}=\frac{d x_{b}(\theta)}{d \theta} m_{f} \cdot L H V_{f}
$$

where $m_{f}$ is the fuel mass injected in the cylinder during the injection timing and $L H V_{f}$ is the lower heating value of the fuel. The fuel mass fraction burned $d x_{b}(\theta) / d \theta$ can be modelled by means of a triple Wiebe's function [29]. The mass of fuel injected through each nozzle is modelled according to [4], whereas the heat transfer rate to the walls of cylinder is predicted according to the Annand method [30]. The engine performance, in term of brake thermal efficiency (BTE), 
electric efficiency, thermal efficiency, energy utilization factor (EUF) and brake specific fuel consumption (BSFC-SFC) are defined as follows:

$$
\begin{gathered}
B T E=\frac{P_{b}}{\dot{m}_{f} L H V_{f}} \\
\eta_{e l}=\frac{P_{e l}}{\dot{m}_{f} L H V_{f}} \\
\eta_{t h}=\frac{\dot{Q}_{t h}}{\dot{m}_{f} L H V_{f}} \\
E U F=\frac{P_{e l}+\dot{Q}_{t h}}{\dot{m}_{f} L H V_{f}} \\
B S F C=\frac{\dot{m}_{f}}{P_{b}} \\
S F C=\frac{\dot{m}_{f}}{P_{e l}}
\end{gathered}
$$

The electric power $P_{e l}$ is evaluated as product of the brake power $P_{b}$ and the alternator electro-mechanical efficiency $\eta_{e m}$. The brake power $P_{b}$ is evaluated as the difference between the indicated power $P_{i n}$ and friction-al power $P_{f r}$, which is considered constant for a given engine speed [4]:

$$
P_{b}=P_{\text {in }}-P_{f r}
$$

Thermal power $\dot{Q}_{t h}$ takes into account the heat transfer rate recovered from the cooling fluid $\left(\dot{Q}_{c o o l}\right)$ and the exhaust gas $\left(\dot{Q}_{e x h}\right)$. The thermal power to the coolant corresponds to the heat transfer to the walls $\dot{Q}_{w}$, which is predicted according to the Annand approach [30]. The thermal power of the exhaust gas $\dot{Q}_{e x h}$ is estimated form the energy balance of the internal combustion engine:

$$
\dot{Q}_{e x h}=\dot{m}_{f} L H V-P_{e l}-\dot{Q}_{c o o l}-\dot{Q}_{m i s c}
$$

where the miscellaneous losses are considered independent on the engine load according to the literature [31]. The main assumption of the adopted for the investigations can be found in literature [27].

\section{Results and Discussion}


The model is validated in terms of BTE and BSFC of the engine running on B0 and B30 at different engine loads. The experimental data are extracted from the literature [26]. Furthermore, a validation of the results predicted by the model in terms of cylinder pressure and heat release rate (HRR) is carried out. The comparison between the experimental and model results in term of BTE and BSFC for diesel (B0) and the diesel/biodiesel blend (B30) is shown in Figure 2 and Figure 3, respectively.

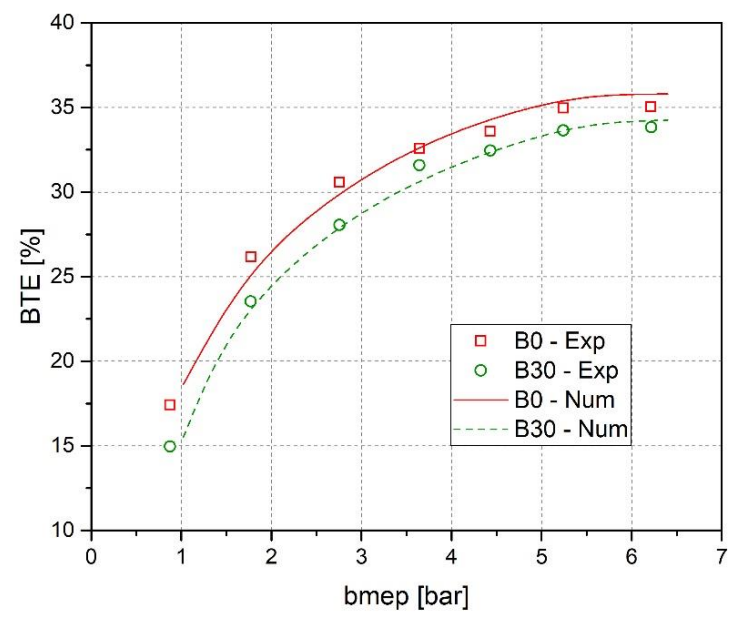

Figure 2. Experimental and Numerical BTE comparison for B0 and B30 at different engine loads.

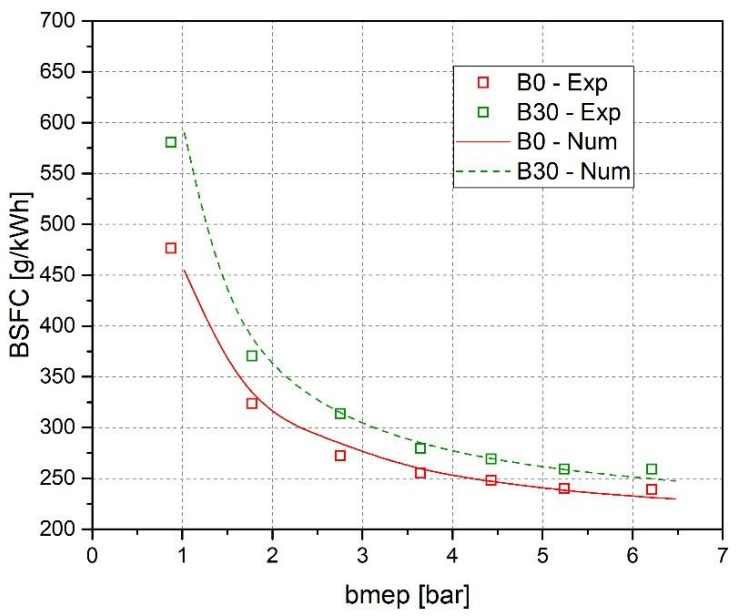

Figure 3. Experimental and Numerical BSFC comparison for B0 and B30 at different engine loads.

It is important to highlight that the BTE increases with the increase of the engine load and the B0 fuel presents a BTE higher than B30 for each engine load. Consequently, the BSFC of B0 fuel is lower than B30 and decreases with increase of the engine load. This is mainly due to the higher density, viscosity and lower LHV of B30 respect to the B0 fuel. Therefore, in order to produce the same amount of energy, more biodiesel/diesel blend fuel is needed. In order to validate the experimental results, a calibration of the combustion parameters is carried out and a good agreement between literature and model results is obtained. 
In order to highlight the differences between engine running on B0 and B30 fuels and validate the model on the results, based on the indicated cycle, the HRR curve for B0 and B30 at 5.3 bar bmep ( $90 \%$ of full load) are shown in Figure 4.

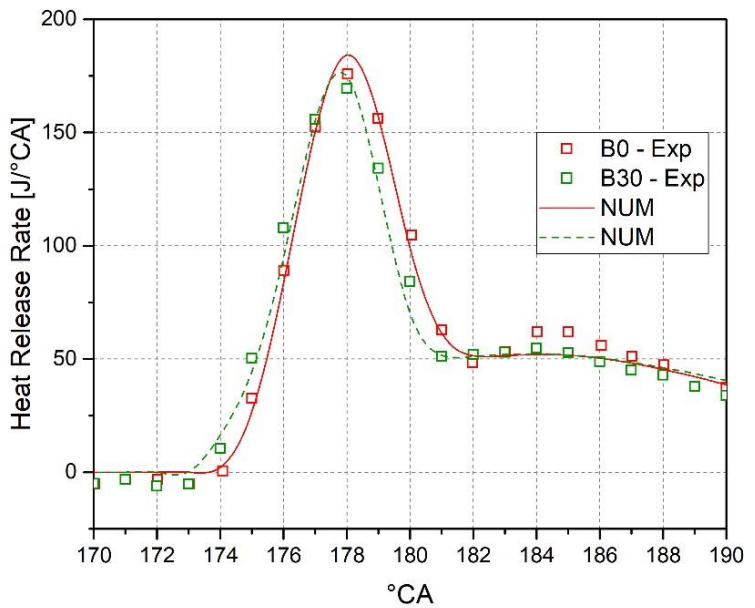

Figure 4. HRR comparison using B0 (a) and B30 (b).

Although the $\mathrm{B} 0$ and $\mathrm{B} 30$ fuels present a similar combustion process, few differences can be observed. The SOC occurs when the HRR becomes positive, and for $\mathrm{B} 30$ is advanced of about $1^{\circ} \mathrm{CA}$ respect to diesel fuel. This finding is confirmed in other works [32-33]. The peak of HRR for B30 is slightly lower than that of B0 fuel because the B30 shows a worst mixing with air and a lower volatility respect to diesel fuel, as well as a shorter ID. It is noteworthy that the numerical results are in good agreement with experimental ones. Since no modifications of the pump and injector settings are made, the start of injection (SOI) is almost identical for all fuels. Further slight differences between numerical and experimental results can be observed in the second phase of combustion (diffusion combustion) in which an experimental slight peak is observed, whereas a smooth curve for the numerical results is predicted.

The proposed numerical model has been adopted to characterise the energy performance of the biodiesel-fired microCHP unit. Figure 5 highlights the numerical energy balance for B0 and B30 fuels as percentages of the fuel input.
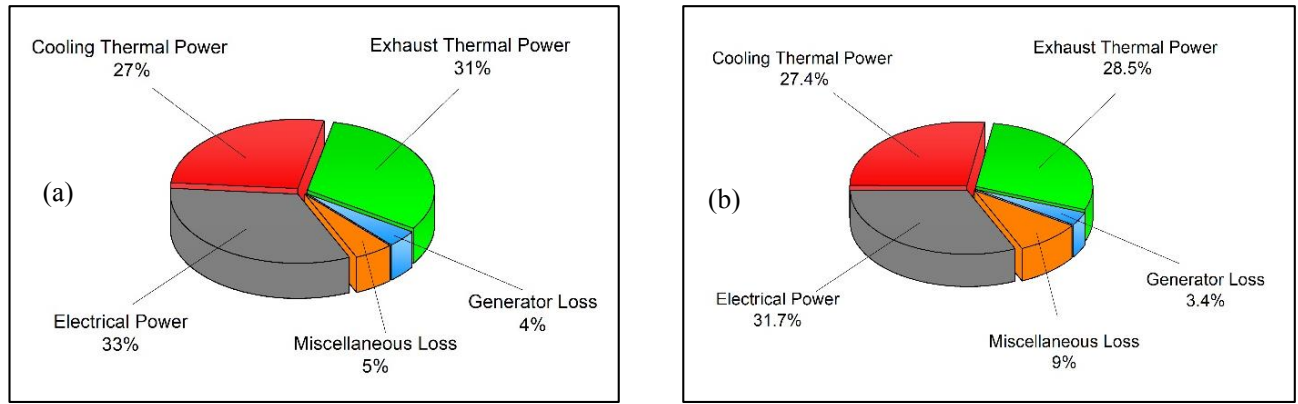

Figure 5. Energy balance of the B0 (a) and B30 (b) -fired micro-CHP system.

The energy utilisation factor of the micro-CHP fuelled with B0 is $91 \%$ and $5 \%$ of the B0 primary energy can not be used for cogeneration purposes. The electric and thermal efficiencies correspond to $33 \%$ and $58 \%$, respectively. In particular, the useful thermal effect is obtained from the energy exploitation of the cooling fluid and exhaust gas $(27 \%$ and $31 \%$ of the fuel input, respectively). Differently, when the micro-CHP system is fuelled with B30 is characterized by an energy utilization factor of $87.6 \%$. This EUF decrease is due to both the electric and thermal efficiencies reductions. The electric 
efficiency decrease is mainly due to the lower LHV, whereas the thermal efficiency reduction is owing to a lower exhaust thermal power. In particular, the thermal power recovered by the exhaust gas is $28.5 \%$, whereas the thermal power recovered by the engine coolant is $27.4 \%$.

\section{Conclusion}

A 0D-thermodynamic model has been developed for the prediction of the performance of a compression ignition engines fuelled by pure diesel fuel (B0) and a diesel/biodiesel blend with a low biodiesel concentration (B30), in order to avoid modifications in the engine architecture (injectors, seals, etc.). The model is capable to predict indicated performance of the engine. The global performance of the engine for diesel and diesel/biodiesel blend was compared. Results show that the BTE and B30 are lower than B0 one, consequently the BSFC increases with increase the amount of biodiesel in the blends. The main reason is due to the lower heating value of B30 in comparison with the diesel fuel. However, the heat release rate for B30 is comparable to diesel fuel at high engine load. Furthermore, B30 shows a lower thermal efficiency mainly due to a lower exhaust power. Consequently, the micro-CHP system fuelled with B30 reveals an energy utilization factor lower respect to the diesel one due to reduction of both electric and thermal efficiency. In order to consider the different properties of biodiesel respect to the diesel fuel a fit process of the combustion parameters has been performed. The heat release curve has been predicted using the model and a good agreement with the experimental results has been obtained. Despite the present work represents a first exploration of the performance evaluation in a small compression ignition engine fuelled with low amount of biodiesel in diesel/biodiesel blend, the study suggests that the 0D thermodynamic model developed can be an accurate tool to predict the performance without implementing complex and highly computational-cost models.

\section{References}

[1] A.K Agarwal, Biofuels (alcohols and biodiesel) applications as fuels for internal combustion engines. Prog Energy Combust Sci, 33, 233-71, (2007)

[2] S.A. Basha, K.R. Gopal, S. Jebaraj, A review on biodiesel production, combustion, emissions and performance. Renew Sustain Energy Rev, 13, 1628-34 (2009)

[3] H. Raheman, SV. Ghadge, Performance of diesel engine with biodiesel at varying compression ratio and ignition timing, Fuel, 87, 2659-66, (2008)

[4] J.B. Heywood, Internal Combustion Engine Fundamentals, McGraw-Hill, New York (1988)

[5] E. Galloni, G. Fontana, R. Palmaccio, Numerical analyses of EGR techniques in a turbocharged spark-ignition engine, Applied Thermal Engineering, 39, 95-104, (2012)

[6 ] S. Mauro, R. Şener, M. Z. Gül, R. Lanzafame, M. Messina, S. Brusca, Internal combustion engine heat release calculation using single-zone and CFD 3D numerical models, International Journal of Energy and Environmental Engineering, 9, $215-226$, (2018)

[7] S. Bova, T. Castiglione, R. Piccione, F. Pizzonia, A dynamic nucleate-boiling model for $\mathrm{CO}_{2}$ reduction in internal combustion engines, Applied Energy, 143, 271 - 282, (2015)

[8] X. Zhen, Y. Wang, S. Xu, Y. Zhu, C. Tao, T. Xu, M. Song, The Engine Knock Analysis, Applied Energy, 9, 628 $636,(2012)$

[9] T. Castiglione, P. Morrone, L. Falbo, D. Perrone, S. Bova, Application of a model-based controller for improving internal combustion engines fuel economy, Energies, 13(5), 1148, (2020)

[10] A. Algieri, P. Morrone, D. Perrone, S. Bova, T. Castiglione, Analysis of multi-source energy system for small-scale domestic applications. Integration of biodiesel, solar and wind energy, Energy Reports, 6, 652 - 659, (2020) 
[11] N. Kim, I. Ko, K. Min, Development of a zero-dimensional turbulence model for a spark ignition engine, International Journal of Engine Research, 20 (4), 441 - 451 (2018)

[12] S. Grasreiner. Combustion modeling for virtual SI engine calibration with the help of 0D/3D methods. Ph.D. Thesis, Technical University of Bergakademie Freiberg, Freiberg, (2012).

[13] V. De Bellis, E. Severi, S. Fontanesi and F. Bozza. Hierarchical 1D/3D approach for the development of a turbulent combustion model applied to a VVA turbocharged engine. Part I: turbulence model. Energy Procedia, 45, 829-838, (2018)

[14] A. Algieri, S. Bova, C. De Bartolo, A. Nigro,"Numerical and Experimental Analysis of the Intake Flow in a High Performance Four-Stroke Motorcycle Engine", Journal of Engineering for Gas Turbines and Power; 129 (4), (2007)

[15] A. Algieri, S. Bova, and C. De Bartolo, "Experimental and Numerical Investigation on the Effects of the Seeding Properties on LDA Measurements," ASME J. of Fluids Engineering, 127, 514 - 522, (2005)

[16] A. Algier, M. Amelio, S. Bova, P. Morrone, Energy Efficiency Analysis of Monolith and Pellet Emission Control Systems in Unidirectional and Reverse-Flow Designs, SAE International Journal of Engines, 2, 684 - 693, (2010)

[17] M. Zheng, Reader GT, Energy efficiency analyses of active flow aftertreatment systems for lean burn internal combustion engines. Energy Conversion and Management, 45, 2473 - 2493, (2004)

[18] A. Güthenkea, D. Chatterjeea, M. Weibela, N. Waldbüßera, P. Kočí, M. Marek, M. Kubíček, Development and application of a model for a $\mathrm{NO}_{x}$ storage and reduction catalyst, Chemical Engineering Science 62, 5357 - 5363, (2007)

[19] C.D. Rakopoulos, D.C. Rakopoulos, E.G. Giakoumis, D.C. Kyritsis, Validation and sensitivity analysis of a two zone Diesel engine model for combustion and emissions prediction, Energy Conversion and Management, 45, 14711495, (2004)

[20] J. Galindo, J.M. Luján, J.R. Serrano, V. Dolz, S. Guilain, Description of a heat transfer model suitable to calculate transient processes of turbocharged diesel engines with one-dimensional gas-dynamic codes, Applied Thermal Engineering, 26, 66-76, (2006)

[21] B. Jayashankara, V. Ganesan, Effect of fuel injection timing and intake pressure on the performance of a DI diesel engine - A parametric study using CFD, Energy Conversion and Management, 51, 1835-1848, (2010)

[22] P. Morrone, A. Algieri, T. Castiglione, D. Perrone, S. Bova, Investigation of the energy performance of multi-source integrated CHP systems for small-scale applications, AIP conference Proceedings, 2191, 020115, (2019)

[23] N. Abbe, V. Claude, R. Nzengwa, R. Danwe, Z.M. Ayissi, M. Obobou, A study on the 0D phenomenological model for diesel engine simulation: Application to combustion of Neem methyl esther biodiesel, Energy Conversion and Management, 89, 568-576, (2015)

[24] T.K. Gogoi, D.C. Baruah, A cycle simulation model for predicting the performance of a diesel engine fuelled by diesel and biodiesel blends, Energy, 35, 1317-1323, (2010)

[25] A.S. Ramadhas, S. Jayaraj, C. Muraleedharan, Theoretical modeling and experimental studies on biodiesel-fueled engine, Renewable Energy, 31, 1813-1826, (2006)

[26] D.H. Qi, H. Chen, L.M. Geng, Y.Z.H. Bian, Combustion Experimental studies on the combustion characteristics and performance of a direct injection engine fuelled with biodiesel/diesel blends, Energy Conversion and Management, 51, 2985 - 2992, (2010) 
[27] D. Perrone, A. Algieri, P. Morrone, T. Castiglione, Energy and Economic Investigation of a Biodiesel-Fired Engine for Micro-Scale Cogeneration, Energies, 14 (2), Article 496, (2021)

[28] H.O. Hardenberg, F.W. Hase, An Empirical Formula for Computing the Pressure Rise Delay of a Fuel from Its Cetane Number and from the Relevant Parameters of Direct-Injection Diesel Engines, SAE paper 790493, SAE Trans., 88, (1979)

[29] S. Awad, E.G. Varuvel, K. Loubar, M. Tazerout, Single Zone Combustion Modeling of Biodiesel from Wastes in Diesel Engine, Fuel, 106, 558-568, (2013)

[30] W.J.D. Annand, Heat Transfer in the Cylinders of Reciprocating Internal Combustion Engines, Proc. Instn Mech. Engrs, 177 (36), 973-990, (1963)

[31] J.Y. Wu, J.L. Wang, S. Li, R.Z. Wang, Experimental and Simulative Investigation of a Micro-CCHP (Micro Combined Cooling, Heating and Power) System with Thermal Management Controller. Energy, 68, 444-453, (2014)

[32] M. Gumus, A comprehensive experimental investigation of combustion and heat release characteristics of a biodiesel (hazelnut kernel oil methyl ester) fuelled direct injection compression ignition engine, Fuel, 9, 2802-2814, (2010)

[33] E. Ozturk, Performance, emissions, combustion and injection characteristics of a diesel engine fuelled with canola oil-hazelnut soapstock biodiesel mixture, Fuel Processing Technology, 129, 183 - 191, (2015) 